\title{
WITTGENSTEIN E AS EXPERIÊNCIAS PSICOLÓGICAS
}

\author{
Arturo Fatturi \\ Universidade Federal de Mato Grosso
}

\begin{abstract}
We start form the principle that the problems about the explanation of the inner world experinecies must be searched in the correct understanding of our ordinary language when we use psychological referring concepts to our psychological experiences. We make, in the first place a surview of the traditional point of view about our language and the problems that appear when we conceive that language is at first descritiptive. We analise some paradoxes that this conception impose to our understand of psychological concepts. Later, we presents the point of view of Ludwig Wittgenstein and the poinit of view that he presentes to us to an adequately surview of our expressions about inner experiences.
\end{abstract}

Keywords: Philosophy, Wittgenstein, concepts, psychology, inner experiences.

Resumo: Parte-se do princípio que os problemas relativos à explicação do mundo interior devem ser buscados na correta compreensão do funcionamento de nossa linguagem ordinária quando usamos conceitos referentes à nossas experiência psicológicas. Primeiramente apresenta-se o ponto de vista tradicional descritivista sobre nossa linguagem e os problemas que surgem quando tentamos com base nesta concepção explicar as experiências interiores. Posteriormente, apresenta-se o ponto de vista de Ludwig Wittgenstein e o diagnóstico que este fornece para que consideremos adequadamente nossas expressões sobre experiências interiores.

Palavras-chave: Filosofia, Witttgenstein, conceitos, psicologia, mundo interior.

I am going to exclude from our discussion questions which are answered by experience. Philosophical problems are not solved by experience, for what we talk about in philosophy are not facts but things for which facts are useful.

Philosophical troubles arises trough seeing a system of rules and seeing that things do not fit in it.

(Wittgenstein's Lectures, 1932-1933) 
Um dos problemas tratados pela Filosofia da Mente diz respeito à interação entre o nosso interior (composto por desejos, crenças, dores, etc.) e o mundo exterior (povoado por coisas tais como cadeiras, pessoas, canetas, etc.). Consideramos o mundo exterior de dois modos. Um deles se mostra através do comportamento que mantemos com relação às coisas externas, comportamento este fundamentado nas relações físicas de possibilidade e de impossibilidade, bem como de causalidade. Outro modo é a forma como consideramos tais coisas externas, e mesmo o próprio comportamento que exibimos.

Assim, temos por um lado o mundo de objetos e, por outro, o nosso mundo interior, que consiste na apreciação e nos motivos do comportamento que apresentamos. Podemos afirmar que um corte no dedo, por exemplo, produz uma transformação visível num objeto (o dedo), enquanto que a dor causada pelo corte (afora casos específicos, isto é, fora da normalidade) não está exatamente no corte, mas sim, que a dor é algo interno ao que diz que a sofre (no caso, o dono do dedo). Esta diferenciação é reforçada pela forma como a própria linguagem é concebida, isto é, como sendo uma descrição de alguma coisa, seja ela interna ou externa. As descrições poderão ser verdadeiras ou falsas e, dessa forma, as palavras e afirmações que dizem respeito ao mundo interior também deverão ser assim concebidas.

Esta dicotomia, apesar de superficialmente descrita, encontra eco na argumentação cartesiana de que o nosso corpo possui relações que não podem ser atribuídas ao nosso espírito (que atualmente denominamos mente). Desse modo, de acordo com a argumentação cartesiana e do senso comum, somos divididos em duas partes, quais sejam, corpo e mente. Cada uma destas partes é uma substância diferente da outra: a substância mental é interior ao indivíduo, enquanto que o corpo, ou substância corporal, é exterior ao indivíduo.

Mesmo que não apelemos à argumentação cartesiana, parece óbvio a todos que há uma distinção entre o nosso comportamento e, por sua vez, as razões pelas quais nos comportamos de uma determinada maneira específica e não de outra. Mais ainda, é também comum dizermos que o comportamento de uma pessoa, por mais que seja observado, não revela as razões pelas quais esta se comportou daquela forma. É óbvio, por exemplo, que uma pessoa que nos pede um copo de água está apresentando um 
comportamento de quem tem sede e quer saciar esta sede. Contudo, do fato de que esta pessoa nos pede água não podemos de maneira simples afirmar, justificadamente, que tal pessoa está, de fato, com sede,. Ou seja, o seu comportamento é óbvio e público, no entanto, os motivos de seu comportamento não são necessariamente análogos. Com isto, reforçaríamos a visão de que o mundo interior (onde estariam contidos os motivos das ações) é privado, enquanto que o mundo externo, do comportamento, é público. $\mathrm{Na}$ linguagem, este ponto de vista assume o seguinte aspecto: as descrições do mundo exterior poderão ser conferidas quanto à sua veracidade ou falsidade através da verificação da informação que veiculam.Todavia, as descrições do mundo interior, apenas serão verificáveis por aquele que as profere.

Este ponto de vista, apesar de pertencer ao senso comum de todas as pessoas, também foi levado ao status de problema filosófico ou de teoria psicológica. Se, por um lado, tais afirmações são compreensíveis no mundo quotidiano, se tornam paradoxais nas teorias psicológicas e quando tratadas como problemas filosóficos.

O problema com o qual pretendemos lidar neste ensaio, está relacionado à linguagem, considerada sob o ponto de vista dos relatos internos, isto é, daquelas afirmações que veiculam informações sobre o interior de outrem, qual seja, daquele que as profere. Dessa forma, afirmações como "tenho sede", "sinto dor de cabeça", "estou triste", e similares, são tratadas como veiculadoras de informação sobre a pessoa que as enuncia. Ainda mais, tais afirmações são comuns e quotidianas e, sob tal aspecto, compreensíveis. Todavia, estas mesmas afirmações se transformam em paradoxos quando perguntamos pela sua justificação ou por sua verdade. Isto, pelo fato de que "dizer" que temos sede, segundo o ponto de vista tradicional, pode ser verdadeiro ou falso, tendo em vista serem relatos de acontecimentos. Teríamos de obter alguma possibilidade de verificar a informação que é relatada para que possamos conferir verdade ou falsidade a estes relatos. Ora, dado que o mundo interno não é público, isto é, não podemos verificá-lo, teremos de confiar no testemunho de quem faz tais relatos. Apenas esta pessoa poderá responder, no momento que alguma dúvida surgir quanto à certeza do relato, pois é ela que possui o mundo interno do qual faz o relato. Se assim for, então, a pessoa que afirma "Estou triste", quando questionada quanto à certeza e correção de seu relato, responderá afirmando: "Sei que sinto tristeza neste momento, pois tristeza é o que ocorre em mim neste momento". Contudo, quanto à alegação de 
conhecimento do que se passa no interior de quem afirma que tem sede, não parece, de todo, suficiente. Senão vejamos: caso duvidemos de sua afirmação, tal pessoa alegará saber o que se passa em seu interior. Se ainda continuarmos a duvidar "Mas como você sabe?", ela poderá alegar que sabe, pois o interior é seu e, sob tal aspecto, não poderá estar enganada ${ }^{1}$.

Os relatos de determinadas experiências interiores podem não ser diferenciados dos relatos que informam algo sobre o mundo exterior. Por exemplo, a afirmação "Tenho um dente quebrado" poderá ser verificada por qualquer dentista. Ou seja, quando se trata de uma afirmação que veicula informação sobre o mundo exterior, temos meios variados de verificar a veracidade e a justificação do relato. Relatos de experiências interiores, no entanto, não possuem formas de verificação análogas. Certamente que aqui devemos fazer uma distinção quanto ao uso de "interno", qual seja, alguma coisa pode ser interna ao corpo, mas ser verificável, como, por exemplo, uma úlcera ou gastrite (entre outros casos). Neste caso, o evento não é público, mas poderá ser tornado público segundo alguns métodos da medicina. Outro uso de "interno" é o dos relatos de experiências internas psicológicas, pois estes dizem respeito a eventos que apenas a pessoa que os relata poderá verificá-los, tal como acima se dá com o exemplo de "tristeza". Não temos métodos de verificar se a tristeza alegada é ou não verdadeira. Temos apenas o comportamento da pessoa, ou seja, seu comportamento nos indicará o quanto podemos crer no seu relato. Entretanto, o comportamento parece apenas nos fornecer uma forma indireta de verificação, pois comparamos o que a pessoa diz com casos padrão de comportamento de tristeza, de dores ou de sede e com o nosso caso próprio, quando estamos naquelas idênticas condições. Aqui não atingimos um grau de certeza verificável e justificada.

Esta dicotomia foi objetivo de investigação, tanto pela tradição filosófica quanto pela tradição psicológica. Em primeiro lugar, temos de observar que a alegação de justificativa exibida por "Sei" em "Sei que estou triste", nos remete a uma instância privada. Nesta, é assumido por quem faz tal afirmação, que seria paradoxal dizer "Sinto-me triste" e, por sua vez, não saber se é tristeza que sente ou outra coisa qualquer. Com isto, a afirmação remete à possibilidade de verificação da veracidade de "Sei que estou triste" para o interior de quem profere

${ }^{1}$ Como comenta Gilbert Ryle em The Concept of Mind, sob tal aspecto: a consciência é um fluxo contínuo de pensamentos e estados interiores, logo, afirmar que não sabe o que se passa em seu interior não parece racional, pois, pensamentos e estados interiores é o que constitui a consciência. 
este relato. Logo, é assumido tacitamente que a verificação de um relato de experiência interna na primeira pessoa é uma informação fundamentada no interior da pessoa que faz tal relato. Esta observação ajuda a deixar claro que apesar de não estar defendendo um Dualismo (interior/exterior), a alegação acima o tem como pressuposto. Por Dualismo pretendemos identificar o ponto de vista segundo o qual, nós seres humanos (e talvez outros animais) possuímos tanto um corpo que segue as regras da fisica e das ciências naturais, portanto um mundo público, externo, quanto um mundo interior. Quanto a este mundo interior, segundo o Dualismo, a ciência natural não poderá afirmar nada, pelo menos, nada justificado. Ainda, segundo o Dualismo, estados mentais como "emoção", "desgosto", "descrença” e "expectativa", para citar alguns, são fenômenos que ocorrem no interior do indivíduo, mas que tem alguma repercussão no corpo e, portanto, podem ser apreciados publicamente. Assim, retomando o relato de experiência interna, o dualista assume como verdadeira a tese de que a justificação interna é um meio de verificação, tendo em vista que ocorre no mundo interno de quem faz tal relato. Logo, a veracidade da informação veiculada somente poderá ser verificada por esta mesma pessoa. Outras pessoas, afora a auto justificação fornecida, poderão apenas observar o comportamento desta pessoa, pois o comportamento é uma expressão de seu mundo interior, ainda que não possamos afirmar que que isto é fidedigno em todos os casos. Ora, o Dualismo assume então que (a) cada pessoa possui uma mente da qual é dona (ou que é ela), (b) a mente é algo interno à pessoa (a mente está no corpo, mas não é o corpo), (c) a mente não é pública, mas sim privada, (d) há uma relação entre interno e externo e, (e) apenas o dono da mente a ela tem acesso.

Deixaremos para mais tarde as críticas que podemos fazer a este ponto de vista e passaremos para o segundo ponto de vista mais tradicional, que é oferecido na tentativa de solucionar o problema interno/externo, o Materialismo. Segundo o Materialismo, uma pessoa nada mais é do que todas aquelas partes que pertencem ao seu corpo. Ser uma pessoa significa ser o corpo que se é, não havendo nada além disso. Assim, para o Materialismo não há mundo interior que serviria de pano de fundo e explicação para os relatos de experiência pessoal. De fato, alegará o Materialista, não somos “dois em um”, mas um (corpo) apenas. Os relatos de experiência interna dizem respeito não a um mundo interno e privado, mas sim, ao próprio corpo ou a estados que a ele podem ser reduzidos. A afirmação "Tenho sede" é um relato daquilo que ocorre em nosso corpo e, caso alguma justificativa for necessária, bastará fazer alguns exames específicos para a "falta de água no corpo". A grande vantagem do Materialismo 
é, a princípio, a eliminação de um mundo misterioso e metafísico (tendo em vista não ser passível de verificação), do qual os relatos de experiência retirariam a suas justificativas. O Materialismo reduz ao corpo os fenômenos que no Dualismo pertencem ao mundo interno.

Outro ponto de vista oferecido é o Epifenomenalismo, segundo o qual há uma interação entre o interno e o externo. Contudo tal relação se dá a partir do corpo para o interior, e não o contrário. Ou seja, tanto quanto no Dualismo, há um mundo interno e um mundo externo, mas as relações entre ambos são assimétricas, se assim podemos dizer, pois o corpo tem influência nos estados interiores, não se dando o contrário. Dessa forma, um relato de experiência interna é, para o Epifenomenalista, um relato do mundo interior, mas a sua justificação não está no interior, e sim, no corpo. Ora, o Epifenomenalismo fornece uma combinação de Dualismo e Materialismo, contudo, recolhe apenas o que menos problemas parece causar, tendo em vista que não nega o mundo interior, mas nega seu status metafísico: o mundo interior é físico e verificável. Recolhe do Materialismo o argumento de que o mundo exterior (o corpo) é o que cada pessoa é, mas não se compromete com a redução de um ao outro.

Certamente que muitos outros aspectos destes pontos de vista poderiam ser salientados e contra-argumentados, todavia para os fins que aqui nos são interessantes, cremos que a exposição de cada um permite introduzir o ponto que pretendemos desenvolver. Este diz respeito ao fato de que ao tratarmos com os paradoxos da relação entre interior e exterior e afastarmos tanto o mundo metafísico do Dualismo, bem como as reduções do Materialismo e as relações assimétricas do Epifenomenalismo, corremos o risco de tentar construir uma outra teoria da mente a partir de dados empíricos, a fim de superar aqueles pontos de vista. Em suma, pretendemos argumentar que não se trata de uma "solução empírica", o que nos permitirá compreender o mundo interno ou se ainda devemos utilizar a expressão "relação" entre interno e externo. O ponto de vista que procuramos desenvolver é uma análise conceitual que visa à clareza no uso dos conceitos que utilizamos para compreender os relatos de experiências do mundo interior, contrapondo-se a uma investigação empírica dos "objetos" designados pelos conceitos empregados pelo Dualismo, Materialismo e Epifenomenalismo. Nosso ponto de vista é, então, fundamentado basicamente na filosofia de Ludwig Wittgenstein, exposta tanto nas Investigações Filosóficas, quanto em outras de suas obras. 
Os argumentos críticos fundamentais que são lançados contra o Dualismo, em primeiro lugar, fundamentam-se no fato de que se aceitarmos os argumentos básicos do Dualismo e buscarmos fornecer uma explicação sobre como se dá a influência tanto do corpo sobre a mente quanto da mente sobre o corpo, chegaremos, irremediavelmente, a uma descrição de eventos físicos. Ou seja, caso aceitemos que eventos físicos produzem eventos mentais (por exemplo, a carência de certos componentes químicos no sangue e a tristeza ou depressão), não teremos problemas maiores em descrever quais seriam os eventos físicos envolvidos na situação. Entretanto, enfrentaríamos grandes dificuldades para explicar "como" um evento físico "causa" ou "produz" um evento mental. Da mesma forma, se aceitamos a outra ponta do argumento Dualista, qual seja, que um evento mental poderia "causar" um evento físico, por mais que procurássemos descrever as interações não descreveríamos nada mais que eventos físicos. Para desenvolver o raciocínio em questão suponhamos que aceitemos a ideia de que "algo" mental possa produzir um evento físico. Tomemos como exemplo o nervosismo acompanhado por sudorese nas mãos e a inquietação que supomos serem "causados", por exemplo, pela expectativa de uma entrevista de emprego ou de uma avaliação. A tentativa de descrever em que consiste a expectativa não consistirá em outra coisa que não seja a descrição de eventos físicos, e não alguma coisa mental. Mesmo que aleguemos que a "expectativa” é um pensamento, encontraremos dificuldades para explicar como um evento "não-físico" causa um evento físico, tendo em vista que eventos físicos são, em circunstancias normais, causados por outros eventos físicos (se pretendemos manter a racionalidade do que compreendemos por eventos físicos). Por outro lado, o Dualista poderia alegar que a mente não é um objeto do mundo, e sim, uma propriedade do cérebro, uma propriedade "não física” que supervém ao cérebro (físico). Tal alegação, contudo, traz consigo certos paradoxos: primeiramente, a afirmação de que a mente supervém ao cérebro, não explica como se dá esta superveniência. Portanto, tal alegação carece de conteúdo explicativo, pois em vez de justificar a causação do não físico ao físico, cria uma relação metafísica a fim de fornecer uma explicação. Em segundo lugar, sendo a mente algo "não físico" teríamos de encontrar, ou postular, a existência de alguma característica específica do mental que também pertencesse ao físico, para que assim pudéssemos justificar a influência mútua. Ora, se há alguma característica comum a ambos, ao que 
parece, a distinção entre mental e físico (cérebro) deverá consistir em apenas algumas características únicas pertencentes a cada uma das substâncias, para que assim os possamos diferenciar. Todavia, dada a argumentação de que o mental é algo "não físico" e que o cérebro é algo físico, então, encontrar uma característica de uma substância não física em uma outra substância física, parece contradizer a própria distinção. A superveniência, sob tal ponto de vista, também não é uma explicação.

Mas, se as coisas são paradoxais para a argumentação Dualista, não é diferente para o Materialista. Podemos dizer que o Materialismo busca, por um lado, identificar estados da mente com estados físicos (do cérebro), ou, por outro, reduzir a mente ao cérebro. Entretanto, se um estado mental é um estado físico, então, certas características dos estados físicos podem, logicamente, ser atribuídas aos estados mentais. Ora, é possível, seguindo esta linha de raciocínio, informar tanto a localização da tristeza quanto uma expressão numérica de sua intensidade ou magnitude, tal como se poderia fazer com um evento físico (por exemplo, a intensidade do batimento cardíaco). Se isto fosse possível, teríamos tristezas de magnitude 1 a 10, para, por exemplo, classsificar casos de depressão. Isto, contudo, não parece ser o que pretende afirmar o Materialista, apesar de ser uma decorrência de seu argumento. Ainda mais, se é esta a pretensão, então deveríamos obter um método de verificação destas expressões numéricas, tendo em vista que afirmamos algo que busca ser verdadeiro e verificável. Talvez mais paradoxal ainda seria afirmar que conceitos como "honra", "coragem" se referem a algo físico. Talvez o Materialista ainda pudesse argumentar contra isto dizendo que tais termos pertencem ao vocabulário popular e, portanto, não entrariam em um vocabulário científico. Entretanto, termos como identidade ainda continuariam mantendo seu significado, isto é: ser o mesmo que. Portanto, se uma emoção "é o mesmo que", um estado físico então, isto implicaria no fato de que a emoção teria de ser localizável tanto quanto um estado físico e, para todos os efeitos, uma emoção não é, necessariamente, localizável (ainda que a emoção de alegria possa ser vizualizada no rosto).

Quanto aos argumentos do Epifenomenalismo caberia questionar qual a necessidade de postular estados mentais, quando as descrições destes fenômenos nada mais seriam do que descrições de estados físicos. Sendo assim, não haveria razão para manter o postulado metafísico da existência de uma "substância" que, de qualquer forma, não teria qualquer função explicativa quanto à compreensão do mundo interior. 


\section{III}

Uma alternativa ao Materialismo, Dualismo e Epifenomenalismo é o ponto de vista do Funcionalismo ${ }^{2}$. A ideia básica do Funcionalismo é a de que todo o tipo de estado mental (aquilo que ocorre no mundo interior) é fruto de um conjunto de relações causais nas quais estão envolvidas (1) os efeitos do meio ambiente sobre o corpo, (2) as relações entre estados mentais e (3) as relações dos estados mentais com o comportamento corporal ${ }^{3}$. Resumidamente, podemos dizer que o Funcionalismo não está interessado em reduzir a mente ao cérebro (corpo) ou vice-versa. Antes, o argumento central do Funcionalismo é a afirmação de que não é possível reduzir um ao outro, tendo em vista que a mente é uma função do cérebro. A mente "ocorre" no cérebro, mas não se reduz a este. A mente é instanciada pelo cérebro, tendo em vista a constituição neurofisiológica que o cérebro possui. Aqui é irresistível a analogia com os computadores ${ }^{4}$, pois a mente (o software) apesar de estar no cérebro (hardware) não é uma parte do mesmo. Um exemplo mais interessante é a analogia com o jogo de xadrez ${ }^{5}$. No xadrez temos as peças que são tocadas e movidas no tabuleiro e as regras para mover peças, contar pontos, etc. Não importa, contudo, qual o tipo de material de que as peças são feitas (podemos inclusive jogar xadrez mentalmente ou sem peças, como num jogo virtual, por exemplo). O importante é conhecer as regras e o objetivo do jogo. Mas, as regras e os objetivos não são parte do "material” com que se move as peças. As regras são instanciadas em cada jogada que fazemos. Isto mostra que o jogo de xadrez possui uma realidade independente do material que é utilizado para desempenhar o jogo. $\mathrm{O}$ mesmo ocorre com com as relações entre cérebro e mente. $\mathrm{O}$ funcionamento mental seria análogo ao do jogo de xadrez no sentido de que a mente é instanciada pelo cérebro, mas não poderia ser reduzida a este. De fato, não

\footnotetext{
${ }^{2}$ Ao tratar do funcionalismo apenas nos ateremos ao seu projeto de constituir-se numa explicação da relação interior/exterior ou corpo/mente.

${ }^{3}$ Maiores desenvolvimentos dos argumentos e contra-argumentos do e ao Funcionalismo, podem ser encontrados em Paul M. Churchland, Matéria e Consciência, UNESP, 2004, p. 67-77 e em João de Fernandes Teixeira, Mente, Cérebro e Cognição, Vozes, 2000, Caps. VI e VII.

${ }^{4}$ O filósofo norte-americano Hilary Putnam publicou em 1975 um artigo intitulado Minds and machines, onde as relações mente/cérebro são concebidas do ponto de vista da inteligência artificial, onde as relações mente/cérebro são concebidas do ponto de vista da inteligência artificial, baseando-se numa analogia entre mentes, cérebros e computadores digitais. Mais sobre este ponto em João de F. Teixeira, op. cit., p. 127.

${ }^{5}$ Encontrada em João de Fernandes Teixeira, op. cit., p. 125.
} 
podemos afirmar que as regras do jogo estão nas peças ou que apenas um tipo de peça poderia instanciar as regras do jogo. Certo é que será necessário algum tipo de material para que as regras sejam instanciadas. O mesmo ocorre com as relações entre a mente e o cérebro: a mente é uma função do cérebro, apesar de não ser redutível a ele. Um exemplo poderá trazer maior clareza ao ponto. Tomemos a "dor": ela resulta de traumas ou danos ao corpo; causa sofrimento, irritação; podemos tomar algumas medidas práticas par aliviar a dor, etc. Portanto, todo estado que apresentar estas características será uma dor. Outros estados mentais tais como "sensações", "medos", “tristezas” ou "angústias” também podem ser definidos através de seus papéis funcionais ${ }^{6}$. Entretanto, se as coisas se passam desta forma, então, qualquer sistema (seja lá qual for a sua constituição) que produza o mesmo tipo de comportamento deverá possuir os mesmos estados mentais. $\mathrm{O}$ funcionalista não teria problemas em admitir que isto é correto: mesmo um alienígena que possuísse um sistema nervoso muito diferente do nosso, mas que executasse as mesmas funções de um sistema nervoso terráqueo, possuiria vida mental igual a da população da terra ${ }^{7}$.

O objetivo da explicação acima é esclarecer que o funcionalismo busca ser uma alternativa aos pontos de vista apresentados anteriormente, pois, ao mesmo tempo em que aceita o Dualismo (aceita a existência de estados mentais) não os pressupõe como independentes ontologicamente do cérebro. Ao mesmo tempo não é incompatível com o Materialismo, tendo em vista que aceita o argumento de que apenas um cérebro material poderia instanciar uma mente ou ter funções mentais. Contudo, o Funcionalista não aceitaria o ponto de vista de um Materialismo reducionista, pois parte do princípio de que a mente não pode ser reduzida ao cérebro.

Entretanto, alguns argumentos podem ser lançados contra o Funcionalismo.

Primeiramente, se todo o sistema que apresentar tarefas tais quais um cérebro pode ser tomado como podendo instanciar uma mente, então, a possibilidade de existirem vários sistemas que instanciem mentes será enorme. Teríamos de poder saber "o que não possui mente”. Isto, contudo, seria o mesmo que perguntar "qual a marca distintiva do mental?". Por sua vez, a resposta "ser instanciado por um cérebro", não traz luz à questão. Ora,

${ }^{6}$ CHURCHLAND, op. cit., p. 68.

${ }^{7}$ João de Fernandes Teixeira, op. cit., p. 125 
não podemos atribuir intencionalidade a qualquer objeto, mas apenas aos que se comportarem de determinada maneira, a saber: de forma a instanciar uma mente. O que, de fato, retorna ao ponto inicial "o que é uma mente para que possa ser instanciada?”. Em segundo lugar, dizer que a mente é uma função do cérebro não é uma resposta esclarecedora o suficiente para que possamos compreender as relações entre ambos, ou seja: como se dá a passagem do cérebro para a mente?

Não interessa aqui elaborar uma descrição pormenorizada dos argumentos funcionalistas nem, tampouco, dos argumentos contrários a ele. $\mathrm{O}$ fato é que o programa Funcionalista gerou enorme pesquisa empírica para encontrar detalhes da organização funcional que é capaz de permitir que seres possuam mentes. Além disso, o funcionalismo gerou o ponto de vista de que sistemas artificiais poderiam "ter" mentes, através da analogia com o computador digital. Todavia, toda a argumentação funcionalista centra-se no argumento básico de que somos seres que possuem tanto mundo mental (não físico), quanto mundo material (físico). Sob tal aspecto, o programa Funcionalista é herdeiro da tradição que compreende nossa linguagem como essencialmente descritiva: há descrições de certos eventos internos, bem como de eventos externos.

\section{IV}

Porém, o Funcionalismo é uma tentativa de responder a um ponto de vista anterior, qual seja, o Dualismo. Assim, os enganos que geram o Dualismo ainda estão presentes no Funcionalismo, bem como no Materialismo e no Epifenomenalismo. Para todos estes pontos de vista quanto ao mundo interno, a linguagem trabalha apenas de uma maneira: ela descreve; portanto, relatos de experiências internas devem ser compreendidos tal como relatos de eventos externos. Tal ponto de vista é análogo a afirmação de que a linguagem é dividida em duas partes, tendo em vista que é composta por palavras faladas ou escritas e, por outro lado, pelo significado destes sons e palavras. Ainda, o significado "não" é a palavra, apesar de que as palavras são necessárias para a veiculação do significado ${ }^{8}$. Há, então, uma diferença entre a palavra e o significado: enquanto que a primeira é algo físico (pode ser escrita de várias

\footnotetext{
8 João de Fernandes Teixeira, op. cit., p. 128, onde 0 autor usa esta dicotomia da linguagem em comparação com a mente que, para o Funcionalista, é instanciada pelo cérebro; da mesma forma como o significado é instanciado pela palavra.
} 
maneiras, pode ser datilografada, lida, observada, etc.), o significado é algo "imaterial" que pertence a uma outra ordem.

Tal suposição é o mote das primeiras páginas do Blue and Brown Books, de Ludwig Wittgenstein. Ora, tendo em vista que o significado não é a palavra, parece óbvio perguntarmos “o que é o significado?”, todavia, dirá Wittgenstein que, se em vez de fazermos esta pergunta ${ }^{9}$, a elaborássemos da seguinte maneira "O que é uma explicação de significado?", nos ateríamos à gramática da expressão "explicação de significado". Isto nos ensinaria algo quanto à gramática da palavra significado e nos protegeria contra a tentação de buscar um objeto ao qual poderíamos chamar "o significado". Tal afirmação nos mostra o tipo de investigação que Wittgenstein propõe para as relações entre interno e externo.

O ponto de partida de Wittgenstein é que os problemas filosóficos, tal como o da distinção entre mundo interno e mundo externo, são oriundos da má compreensão do funcionamento de nossa linguagem. Tal como é demonstrada na citação referida acima do Blue Book, ou seja, a tentativa é a de entender o que é uma explicação de significado, e sob tal aspeto, se trata de uma investigação conceitual. Esta investigação parte do ponto de vista aceito quanto ao funcionamento da linguagem. Com este objetivo Wittgenstein apresenta a citação de um excerto das Confissões de Santo Agostinho, na primeira seção das Investigações Filosóficas. o objetivo é o de apresentar uma teoria ou concepção do funcionamento que gera uma quantidade de problemas para o filósofo.

Resumidamente podemos dizer que para Wittgenstein, o ponto de vista aceito, e problemático, é o da crença de que a linguagem funciona apenas de uma maneira, qual seja, a de elaborar descrições. Tal descrição obtém sua veracidade através da "definição ostensiva", isto é, através de um tipo de definição que liga uma palavra a um objeto. Assim, de acordo com este tipo de definição a palavra "caneta" adquire seu significado quando apontamos para o objeto que ela designa. Este objeto é o significado daquela palavra. O mesmo pode ser dito para todos os substantivos. Quando aplicada aos substantivos que designam objetos "concretos", tal tipo de definição não apresenta problemas maiores. Os problemas surgem quando tratamos com

\footnotetext{
9 Wittgenstein várias vezes neste texto afirma que perguntas iniciadas com "O que é...?", são oriundas das ciências. Para ele a Metafísica tem esta característica: faz perguntas como se as respostas pudessem ser dadas tal como nas ciências. Esta seria a principal fonte da metafísica ver B/B, p. 01).
} 
substantivos como "emoção", “dor”, “espírito”, “mente”, “interior”, etc. Para estas palavras não é simples encontrar objetos para os quais deveremos apontar a fim de lhes conferir veracidade. Dizemos que elas designam certas “representações” e estas, por sua vez, não podem ser objetos, logo, apenas resta a opção de serem entidades mentais. Ou seja, substantivos que indicam entidades abstratas, designam representações que estão no nosso interior, mais especificamente em nossa mente, ou no mundo interior de cada um que usa estas palavras. Cada vez que estas palavras são pronunciadas, trazemos para a mente (através da memória), as representações que cada um destes substantivos significa.

Não é o caso de passar em revista toda a argumentação de Wittgenstein quanto à linguagem. Estas noções são suficientes para demonstrar como o problema de entidades mentais é visto. Assim, dado que palavras abstratas possuem como significado certas representações que estão na mente do falante e, necessariamente, na do ouvinte, restará saber como um terá acesso às representações do outro. Tal questionamento é decorrente do argumento de que cada pessoa possui uma mente, a qual não é acessível publicamente. Wittgenstein, entretanto, vai mais longe e afirma que o próprio dono das representações está em apuros, pois como ele poderá saber que as suas representações estão adequadas às palavras que ouve e fala. Ora, tendo em vista que as palavras abstratas estão relacionadas com representações, deve existir algum critério para ligar uma representação determinada com uma palavra determinada, ou seja, qual o critério que liga uma representação a uma palavra? Entretanto, dado que as representações não são públicas, o critério pelo qual uma pessoa liga suas representações com as palavras que designam algo de seu mundo interior, também deve ser privado. Sendo assim, o fato de que consigamos nos comunicar se torna, então, um fato milagroso, tendo em vista que as mesmas palavras podem ser representadas de maneiras diferentes por indivíduos diferentes. Pode ocorrer, também, o contrário: palavras diferentes poderão receber as mesmas representações para diferentes indivíduos. Em suma, ao aceitarmos a definição ostensiva como única maneira de compreender como as palavras adquirem significado e, com isto, compreender o uso significativo da linguagem, encontramo-nos com sérios problemas quanto à compreensão das palavras do vocabulário psicológico.

Wittgenstein não aceitará a ideia de que o uso significativo da linguagem funda-se na indicação de objetos ou representações. $O$ uso 
significativo fundamenta-se, segundo ele, na aplicação de palavras segundo regras. São as regras que nos servem de guias para o uso e não sua relação com os objetos (internos ou externos). Além disso, as regras são sempre públicas, pois aprendemos a usar as palavras através do ensino que recebemos. Sendo assim, enfrentamos o seguinte problema: como entender o uso das palavras do vocabulário psicológico e perceptivo, tendo em vista que tais palavras se referem a experiências que apenas o indivíduo que as usa possui? Para enfrentar esta questão, Wittgenstein passa a discutir a possibilidade de uma linguagem privada ${ }^{10}$. Uma linguagem é privada, segundo a definição de Wittgenstein (IF, §243), quando o significado de suas palavras pode ser compreendido apenas por aquela pessoa que as usa e, ainda, as regras que esta pessoa segue podem ser definidas apenas por ela.

Não é nossa intenção repassar toda a discussão empreendida por Wittgenstein quanto ao argumento da linguagem privada. $O$ ponto mais importante são as derivações que daí poderemos fazer. Assim, o resultado da discussão empreendida por Wittgenstein pode ser resumido da seguinte maneira: em primeiro lugar, as palavras do vocabulário psicológico, para serem usadas corretamente, devem ser ensinadas, e, além disso, todo ensino do uso das palavras é público. Logo, conceitos psicológicos necessitam regras públicas. Em segundo lugar, dado que os conceitos psicológicos não adquirem sua significação através do seu uso em primeira pessoa, mas sim, através das regras pelas quais são ensinadas, então o significado não é privado $^{11}$, e sim, público. Então, os conceitos de nosso vocabulário psicológico não necessitam da determinação de algum objeto interno para que possuam significado, e sim, do conhecimento das regras para o seu uso. Ora, isto parece eliminar o mundo interno, pois todas as expressões para as quais tradicionalmente atribuímos significados "internos" ou "mentais" resultam como sendo determinadas exteriormente (isto é, pelas regras de uso).

\footnotetext{
${ }^{10}$ Esta discussão é encontrada nas Investigações Filosóficas a partir da seção 243. Nossa intenção não é a de apresentar toda a argumentação em torno do tema. Ainda, a controvérsia quanto ao propósito da discussão da possibilidade de uma linguagem privada, possui ampla controvérsia a qual não cabe apresentar aqui. O ponto importante que deve ser retido é o seguinte: a discussão da possibilidade da privacidade do significado está ligada à a firmação de Wittgenstein de que o significado é fornecido por regras. Regras são entes públicos, mas o significado de palavras do vocabulário psicológico diz respeito aos sentimentos e emoções de quem faz o relato dos mesmos. O paradoxo se dá, então: no modo como informamos outras pessoas sobre nossos "estados de espírito" de maneira significativa.

${ }^{11}$ A possibilidade da privacidade do significado apenas é pensável se as regras para aplicá-lo já forem aprendidas através do ensino público.
} 
Todavia, esta objeção funda-se no ponto de vista de que alguma razão deverá ser fornecida para a diferenciação entre interno e externo. Porém, tal necessidade é fruto de uma concepção do funcionamento da linguagem, qual seja: a concepção de que a linguagem é essencialmente uma descrição.

O que ocorre na concepção de Wittgenstein é que interno e externo já não designam "lugares" povoados por objetos, pois utilizamos a linguagem não mais segundo o modelo descritivista. É apenas sob tal modelo que as expressões "mundo interno" e "mundo externo" necessitam de evidências para a veracidade de afirmações sobre qualquer um deles. Ou seja, já não se trata de encontrar alguma evidência empírica para diferenciar um do outro ${ }^{12}$. O fato é que não há necessidade de postular dois mundos diferentes, pois a forma como a linguagem é compreendida elimina esta necessidade e, com isto, alguns problemas e paradoxos filosóficos deixam de existir. Isto, porque foi a própria concepção descritividta da linguagem que criou estes paradoxos. Entretanto, isto não significa que a investigação conceitual implique em aplicação da ciência linguística. A linguística poderia nos fornecer apenas dados empíricos sobre palavras e as estruturas das mesmas, mas nesta investigação conceitual, o importante é como usamos os conceitos e o que esperamos como resultado de suas aplicações. Lembramos aqui algo que já foi assinalado mais acima: os problemas da Filosofia não são solucionados através de investigações empíricas, e sim, através de investigações conceituais.

\section{V}

Desta forma, para Wittgenstein a dicotomia entre mundo interior e mundo exterior não existe, tendo em vista que é uma falsa dicotomia criada por nossa maneira de compreender a linguagem. Tal conclusão, entretanto, não parece ser satisfatória. Wittgenstein não fornece, ao que tudo indica um método ou uma teoria que nos permita eliminar e elucidar certas características intrincadas da dicotomia. Mas, a maneira como Wittgenstein considera as questões da filosofia é, de fato, escandalosa para os parâmetros do que esperamos de uma "solução" para os problemas filosóficos. A este

\footnotetext{
12 Em UE, II, iv, p. 64 Wittgenstein diz: "O signo característico do mental parece ser o de que temos de adivinhá-lo em outra pessoa a partir de algo externo e apenas o podemos conhecer a partir de si mesmo. Mas quando uma investigação escrupulosa faz com que este ponto de vista se dissipe, como se se tratasse de fumaça, o que resulta então, não é que o interno é algo externo, senão que "externo" e “interno"já não já não valem como propriedades da evidência.
} 
respeito o Professor Joachim Schulte em sua obra Experience and Expression" ${ }^{13}$ : faz o seguinte comentário: "Parece que todo autor que escreve sobre os conceitos psicológicos deve ser tomado como um Dualista, ou Materialista, como um defensor do Interacionismo ou do Behaviourismo, como um advogado do paralelismo psicofísico ou do Funcionalismo. Em vista de todo este zelo classificatório, Wittgenstein representa um escândalo”. De fato, nas Investigações Filosóficas ele menciona o Behaviourismo, mas apenas porque, a seu ver, constitui-se em uma maneira equivocada de olhar para as coisas ${ }^{14}$. Em outras obras ele menciona os prejuízos do paralelismo psicofísico causados por uma má compreensão dos conceitos psicológicos ${ }^{15}$. Entretanto, devido às suas afirmações quanto à impossibilidade da privacidade do significado, e de que todos os conceitos são aplicados segundo regras públicas, normalmente é tomado por behaviourista. Mas, tal atribuição não se enquadra com outras seções que podemos encontrar em suas obras. De fato, Wittgenstein aceita que o comportamento humano possa servir de base para atribuições de desejos ou de intenções. Todavia, o que uma pessoa faz é apenas um critério para que possamos atribuir a ela crenças e intenções. Outro critério (que não se poderia denominar comportamental) seria a cadeia de justificações que tal pessoa fornece para o que fez ou tinha intenção de fazer. Isto porque o fato de seguir regras e atuar de determinada maneira, não é suficiente para uma atribuição. Quem segue uma regra deve tomá-la como norma de seu agir e, com isto, terá de saber justificar suas ações de acordo com esta regra. Esta é uma das razões pelas quais a privacidade do significado não é aceita, pois o uso das palavras se dá segundo uma normatividade, e não através da ostensão (designar objetos ou representações).

\footnotetext{
${ }_{13}$ Claredon Press, Oxford, 1995: 158-166.

14 IF seção 307: "Não será você um behaviourista disfarçado? Você por acaso não diz que, no fundo, tudo isto é ficção, a não ser o comportamento humano?" - Quando falo de uma ficção, falo de uma fiç̧ão gramatical. Na seção 308, diz: Como se chega ao problema filosófico dos processos e estados anímicos do behaviourismo? - O primeiro passo é inteiramente imperceptível. Falamos de processos e estados e deixamos indecisa sua natureza! Talvez venhamos a saber mais sobre ela - achamos. Mas, exatamente por isto, nos fixamos num determinado modo de ver. (...). Precisamos, pois, negar 0 processo ainda não compreendido em um meio ainda não pesquisado. E assim parecemos, pois, ter negado os processo espirituais. E naturalmente não queremos negá-los!

${ }_{15}$ Nota: Em Zettel, seção 611, diz Wittgenstein: "O preconceito a favor do paralelismo psicofísico é fruto de interpretações primitivas de nossos conceitos. Com efeito, se se admite uma causalidade entre fenômenos psicológicos que não seja mediada fisiologicamente, pensa-se que se está a acreditar numa entidade mental gasosa").
} 
Por fim, tal como Wittgenstein reconhece, nossa linguagem descreve primeiramente uma imagem. Entretanto, nada nos é dito sobre como devemos compreender e utilizar esta imagem. Tudo se passa como se observássemos o comportamento de um ponto - um ponto de luz sobre uma tela, diz Wittgenstein. Podemos observar vários aspectos deste comportamento ou apenas um destes aspectos poderia nos interessar. $\mathrm{O}$ mesmo se dá com o comportamento do ser humano, de acordo com Wittgenstein: ele apresenta várias características, as quais podemos observar. Então, pergunta o interlocutor de Wittgenstein: a Psicologia trata do comportamento? Mas do que trata o psicólogo, contra-argumenta Wittgenstein? O que ele relata? Ele não observa o comportamento humano, em particular suas manifestações? Porém, observa ele, estas manifestações não tratam do comportamento. Elas buscam expressar alguma coisa ${ }^{16}$.

\section{Conclusão}

O ponto de vista de Wittgenstein quanto aos conceitos psicológicos não visa modificar nosso uso quotidiano dos conceitos que expressam experiências interiores. Wittgenstein aceita que nosso uso comum está correto, isto é, os propósitos para os quais é usado não implica em paradoxos. Contudo, segundo ele, em primeiro lugar não devemos tomar este uso comum como fundamentado em uma proto-teoria que o filósofo ou o psicólogo devem desenvolver e "tornar clara". Em segundo lugar, a concepção de que nossa linguagem é um instrumento de comunicação eminentemente descritivo, gera uma série de paradoxos quando tratamos de compreender as afirmações sobre estados psicológicos, as quais denominamos também, afirmações sobre experiências interiores. Ou seja, nossa linguagem serve como instrumento de comunicação e é "usada" para descreverobjetos da realidade. Tal afirmação pode ser paradoxal, mas é a isto que Wittgenstein se refere quando diz que nossa linguagem é adequada para os fins a que se propõe, quais sejam: nosso relacionamento com nossos semelhantes. Contudo, esta imagem muda quando consideramos a linguagem a partir do ponto de vista da epistemologia ou da psicologia, pois nestes o objetivo é explicativo. Ora, as imagens de nossa linguagem comum tais como "ter algo em mente" ou "sentir medo", não devem ser tomadas como descrições. É este

${ }^{16}$ IF II, $179 \mathrm{e}$ 
o problema que faz com que vários filósofos postulem intencionalidade a objetos (estou pensando aqui especificamente em Daniel Dennet), uma vez que "ter a intenção de..." é considerada uma afirmação que só pode ser compreendida se os objetos a que se refere forem conhecidos. Mais acima neste ensaio já tivemos ocasião de apresentar exemplos paradoxais deste tipo de concepção. Por fim, é apenas a partir da correta compreensão da concepção de Wittgenstein sobre a linguagem e como, a partir desta, devemos tratar as expressões de experiências psicológicas, que poderemos determinar corretamente a relação da filosofia da psicologia exposta nas Investigações Filosóficas. Ou seja, as atribuições de Behaviorismo à Wittgenstein partem do princípio de que ele trata as experiências psicológicas e seus relatos de forma tradicional, isto é, segundo o ponto de vista da linguagem descritiva.

\section{Referências bibliográficas}

JOACHIM, S. Experience and Expression. Wittgenstein Philoosphy of Psychology, Oxford: Claredon Press, 1995.

Paul, M. C. Matéria e Consciência. São Paulo: UNESP, 2004.

TEIXEIRA, J. de F. Cérebro e Cognição. Petrópolis: Vozes, 2000.

WITTGENSTEIN, L. Philosophical Investigations. Oxford: Blackwell, 2001. . Blue and Brown Books. New York: Harper, 1965.

. Zettel. $7^{\text {a }}$ ed. Lisboa, 1989.

. Last Writings on the Philosophy of Psychology. vol 1. Oxford:

Blackwell, 1992.

. Last Writings on the Psilosophy of Pscychology. vol 2. Chicago:

Chicago University Press, 1982.

- Lectures on Philosophical Psychlogy 1946-1947. Peter Geach

(Ed.). Chicago: Chicago University Press, 1989. 